\title{
Online Resources for Rotator Cuff Repair: What are Patients Reading?
}

\author{
Brandon T. Goldenberg, B.A., William W. Schairer, M.D., Travis J. Dekker, M.D., \\ Lucca Lacheta, M.D., and Peter J. Millett, M.D., M.Sc.
}

\begin{abstract}
Purpose: The purpose of this study was to use a novel scoring system to evaluate the content and grade the quality of websites that patients may use to learn about rotator cuff repair. Methods: Two search terms ("rotator cuff repair" and "rotator cuff surgery") were entered into 3 Internet search engines (Google, Yahoo, and Bing). We scored the quality of information using a novel scoring system. Website quality was further assessed by the Journal of the American Medical Association (JAMA) benchmark criteria and Health on the Net Foundation (HON) code certification. The readability of the websites was evaluated with the Flesch-Kincaid score. Results: We evaluated 47 websites. The average quality for all websites was $6.47 \pm 5.21$ (maximum 20 points). There was a large difference in scores between the top 5 websites and the remaining websites $(16.30$ vs $5.51, P<.001)$. There was no difference in scores when comparing the 3 different search engines $(P=.85)$. The mean reading level was $10.17 \pm 2.24$. Reading level was not significantly correlated with quality $\left(\mathrm{r}_{\mathrm{s}}=0.14, P=.36\right)$. The average JAMA benchmark criteria score for all websites was $2.34 \pm 1.11$ (maximum 4 points). JAMA criteria score was not significantly correlated with quality $\left(\mathrm{r}_{\mathrm{s}}=0.02, P=.91\right)$. Sites without HONcode certification had higher quality scores $(8.33 \pm 4.80)$ than sites with HONcode certification $(6.18 \pm 4.66)$, but this difference was not statistically significant $(P=.15)$. Conclusion: The quality of patient-level information on rotator cuff repair on the Internet is both incomplete and written at a reading level higher than current recommendations. Information quality is not significantly correlated with reading level or JAMA criteria, and does not depend on the search term used or HONcode certification. Clinical Relevance: Patients having rotator cuff repair may seek information on the Internet; the information may require surgeon clarification.
\end{abstract}

$\mathbf{R}$ otator cuff disorders are one of the most common causes of disability related to the shoulder, ${ }^{1}$ and there has been a dramatic increase in national rates of

From the Steadman Philippon Research Institute (B.T.G., W.W.S., T.J.D., L.L.) and The Steadman Clinic (W.W.S., T.j.D., P.J.M.), Vail, Colorado, U.S.A.

The authors report the following potential conflicts of interest or sources of funding: P.J.M. receives consultancy and royalty fees from Arthrex Inc., Medbridge, and Springer Publishing; owns stock in VuMedi; has research activities supported by the Steadman Philippon Research Institute (SPRI) and Vail Valley Medical Center (VVMC); and receives corporate sponsorships from SPRI, Smith and Nephew, Arthrex, Siemens, and Össur. L.L.'s position at SPRI is supported by Arthrex. The other authors report that they have no conflicts of interest in the authorship and publication of this article. Full ICMJE author disclosure forms are available for this article online, as supplementary material.

This research was performed at the Steadman Philippon Research Institute, Vail, CO.

Received March 18, 2019; accepted June 17, 2019.

Address correspondence to Peter J. Millett, M.D., M.Sc., Steadman Philippon Research Institute, The Steadman Clinic, 181 West Meadow Drive, Suite 400,Vail, CO 81657,U.S.A.E-mail:drmillett@thesteadmanclinic.com

(C) 2019 by the Arthroscopy Association of North America. Published by Elsevier Inc. This is an open access article under the CC BY-NC-ND license (http://creativecommons.org/licenses/by-nc-nd/4.0/).

2666-061X/19326

https://doi.org/10.1016/j.asmr.2019.06.002 rotator cuff repair. ${ }^{2}$ Repairs of rotator cuff tears show excellent outcomes, with statistically significant improvements in most patients. ${ }^{3-11}$ However, from the patient's perspective, the prospect of undergoing a rotator cuff repair can be daunting, from understanding how best to prepare for surgery and undergoing anesthesia to optimal strategies for a successful recovery. To learn about their condition and prepare for surgery, many patients will turn to the Internet as a source of information. Today, it is estimated that 9 of 10 U.S. adults use the Internet, ${ }^{12}$ and $72 \%$ of Internet users report having searched for a health related topic online. ${ }^{13}$ Furthermore, the Internet has been shown to be the preferred source of health information for seniors, a demographic that experiences a very high rate of rotator cuff tears. ${ }^{14,15}$ Physicians believe that the Internet can lead to patients becoming better informed. However, many fear that Internet health misinformation and misinterpretation can lead to unrealistic patient expectations, which can damage the patient-physician relationship ${ }^{16,17}$ and impact patient satisfaction and patient-reported outcomes. ${ }^{18-21}$ Henn et al. ${ }^{22}$ studied the correlation of preoperative expectations and 
postoperative outcomes scores in rotator cuff repair and found that higher preoperative expectations of surgical success was associated with higher postoperative performance on self-assessed outcome scores.

Previous studies have evaluated the quality of online information available to patients undergoing orthopaedic procedures. ${ }^{23-35}$ Given the prevalence of Internet users and searches for health information, as well as the high number of rotator cuff repairs performed each year, it is likely that patients scheduled for rotator cuff repair are likely to search the Internet to learn about the surgery. Thus, it is crucial to evaluate the quality of the online resources for rotator cuff repair.

The purpose of this study was to use a novel scoring system to evaluate the content and grade the quality of websites that patients may use to learn about rotator cuff repair. It was hypothesized that most website quality will be incomplete and not cover the breadth of relevant information related to rotator cuff repair.

\section{Methods}

Websites were selected by using a combination of search terms that patients would be most likely to use to find information about the procedure. These search terms were "rotator cuff repair" and "rotator cuff surgery." Both terms were entered into 3 separate popular search engines (Google, Bing, Yahoo), which resulted in 6 separate searches $(2$ search terms $\times 3$ search engines). Websites were recorded from the top 25 results from each search, for a total of 150 results. The search was completed in September 2018.

Websites were grouped by search term and by search engine. When a duplicate website was identified, the term and search engine was selected based on which combination yielded the top-ranked (i.e., earliest) website for a search. Peer-reviewed primary literature was excluded because it was assumed that these would likely exceed comprehension for most patients and also that most patients would not have access to scientific literature. Video content and content for medical professionals were also excluded because of their intended target audience.

After establishing a final list of included websites that discussed rotator cuff repair, the websites were read and independently scored by 4 different evaluators (B.G., W.S., T.D., L.L.), 3 of whom are sports medicine fellowship-trained orthopaedic surgeons. To score the quality of the websites, an author-derived score with a maximum of 20 points was created. The components of the scoring system were agreed on by all authors who are experienced orthopaedic surgeons and consisted of important aspects through each stage of undergoing a rotator cuff repair. The scoring system consisted of elements of diagnosis, treatment options, surgical factors, and postoperative instructions. Each criterion was assigned a 1-point value. Scores for each of the 4
Table 1. Scoring System to Assess Website Information on Rotator Cuff Repair and Rotator Cuff Surgery

\begin{tabular}{l}
\hline \multicolumn{1}{c}{ Scoring Criteria } \\
\hline Preoperative \\
Signs and symptoms of tear \\
Nonoperative options \\
Surgical options for non-reparable tears \\
Optimal surgical preparation strategies \\
Timing of surgery \\
Surgical \\
Indications \\
Length \\
Surgical option: open or mini-open \\
Surgical option: arthroscopic \\
Anesthesia \\
Risks and complications \\
Outcome (recovery time frame) \\
Postoperative \\
Effect of general health conditions on recovery \\
Duration of hospital stay \\
Immediate post-op instructions (sling, ice, rest, etc.) \\
Pain control \\
Physical therapy instructions \\
Time frame with return to activities of daily living \\
Indications on when to consult your surgeon \\
\hline
\end{tabular}

reviewers were combined and averaged to generate a mean quality score for each website included. The scoring card is shown in Table 1.

Readability of each website was assessed using the Flesch-Kincaid (FK) method, which is measured by Microsoft Word (Microsoft, Redmond, WA). The FK method is a type of readability test that indicates how difficult a passage is to understand in English. It assigns a grade level that corresponds to the highest level of education the reader must have to comprehend the reading. Readability of websites was compared to a fifth-grade standard, a recommendation recently proposed by the Joint Commission. ${ }^{36}$

We used The Journal of the American Medical Association (JAMA) benchmark criteria to assess each website in 4 possible areas: (1) authorship; (2) listing of sources used; (3) disclosure of ownership, sponsorship, funding, conflict of interest; and (4) date of update. One point was awarded for each criteria, making a total of 4 points.

The Health on the Net Foundation (HON), a nonprofit organization accredited to the United Nations, certifies websites that meet their quality and reliability standards. ${ }^{37}$ Each website was assessed for the presence of HONcode certification.

\section{Statistical Analysis}

Statistical analysis was performed using STATA statistical software (Version 14.2, Statacorp, College Station, TX). Independent sample $t$-tests for normally distributed data and Mann-Whitney $U$ test for nonnormally distributed data were used to determine 


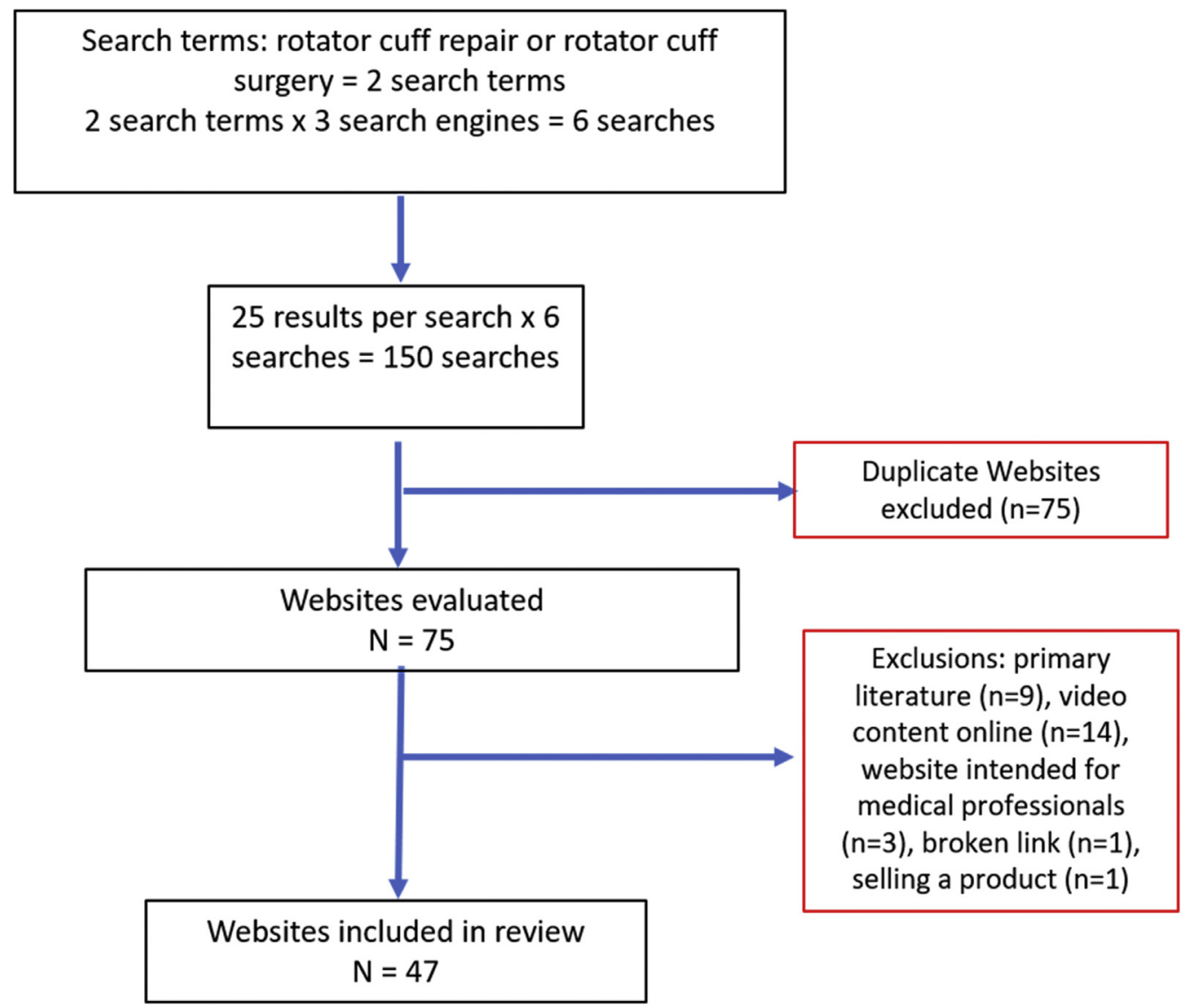

Fig 1. Flow diagram of website selection.

differences between quality score and search term and HONcode certification. Correlation analyses (Spearman rank correlation coefficient for non-normally distributed data) was used to determine association between quality and FK scores and JAMA score. Intrarater and inter-rater reliability for the quality scores were assessed with the single-measure, 2-way randomeffects, absolute agreement definition of the intraclass correlation coefficient. $P<.05$ was used to determine statistical significance. No funding was required for this study.

\section{Results}

Using 2 separate search terms, "rotator cuff repair" and "rotator cuff surgery," the initial search yielded 150 results. Seventy-five websites were removed as duplicates, leaving 75 websites to evaluate (Fig 1). Twentyeight websites were excluded because they were video content (14 sites), peer-reviewed primary literature (9 sites), a website intended for medical professionals (3 sites), broken link (1 site), and selling a product (1 site). After articles were excluded, there were 47 websites left for review (see Appendix 1 for individual website itemized scores). Intrarater reliability was $99.2 \%$ (95\%
CI: $98.6 \%$ to $99.6 \%)$. The inter-rater reliability among all 4 raters was $95.7 \%$ (95\% CI: $92.3 \%$ to $97.6 \%$ ).

Overall, the included websites had an average score of $6.47 \pm 5.21$ of 20 total points. By subsection, this included $1.63 \pm 1.25(32.6 \%)$ of 5 total points for the presurgical subsection, $2.27 \pm 2.17(32.4 \%)$ of 7 total points for the surgical subsection and $2.58 \pm 2.45$ $(32.2 \%)$ of 8 total points for the postoperative subsection. The 3 questions with the highest percentage representation from all articles were "signs and symptoms of a tear $(60 \%)$," "physical therapy $(54 \%)$," and "surgical options: arthroscopic $(51 \%) . "$ The lowest criteria were "effect of general health conditions on recovery $(12 \%), "$ "surgical options for non-reparable tears $(13 \%), "$ and "when to consult your surgeon $(13 \%)$ " (Table 2). The 5 highest scored websites can be found in Table 3. There was a large difference in scores between the top 5 websites and the remaining websites (16.30 vs 5.51; $P<.001$ ) (Table 3). There was no difference in scores when comparing the 2 different search terms $(P=.85)$.

The average FK grade for all websites was $10.17 \pm$ 2.24 (range 5.8-16.4). There was only 1 article that was written at or below a sixth-grade level $(2.1 \%)$. There were 7 websites below an eighth-grade reading level, 
Table 2. Average Website Score by Topic

\begin{tabular}{|c|c|}
\hline & $\begin{array}{c}\text { Percent of } \\
\text { Websites } \\
\text { Including Topic }\end{array}$ \\
\hline \multicolumn{2}{|l|}{ Pre Surgical } \\
\hline Signs and symptoms of tear & $60^{*}$ \\
\hline Nonoperative options & 42 \\
\hline Surgical options for non-reparable tears & $13^{\dagger}$ \\
\hline Optimal surgical preparation strategies & 21 \\
\hline Timing of surgery & 26 \\
\hline \multicolumn{2}{|l|}{ Surgical } \\
\hline Indications & 44 \\
\hline Length & 14 \\
\hline Surgical option: open or mini-open & 42 \\
\hline Surgical option: arthroscopic & $51^{*}$ \\
\hline Anesthesia & 18 \\
\hline Risks and complications & 24 \\
\hline Outcome (recovery time frame) & 34 \\
\hline \multicolumn{2}{|l|}{ Postoperative } \\
\hline Effect of general health conditions on recovery & $12^{\dagger}$ \\
\hline Duration of hospital stay & 17 \\
\hline $\begin{array}{l}\text { Immediate post-op instructions } \\
\text { (sling, ice, rest, etc.) }\end{array}$ & 48 \\
\hline Pain control & 36 \\
\hline Post-op restrictions & 40 \\
\hline Physical therapy instructions & $54^{*}$ \\
\hline Time frame with return to activities of daily living & 39 \\
\hline Indications on when to consult your surgeon & $13^{\dagger}$ \\
\hline
\end{tabular}

*Top 3 represented by all websites.

${ }^{\dagger}$ Bottom 3 represented by all websites.

which made up $14.8 \%$ of the total articles. Overall, readability was not significantly correlated with quality $\left(\mathrm{r}_{\mathrm{s}}=0.14, P=.36\right)$.

There were 14 websites $(29.7 \%)$ that were HONcode certified. Sites without HONcode certification had higher quality scores $(8.33 \pm 4.80)$ than sites with HONcode certification $(6.18 \pm 4.66)$, but this difference was not statistically significant $(P=.15)$ (Table 3$)$.

The average JAMA benchmark criteria score for all websites was $2.34 \pm 1.11$ of a maximum 4. JAMA criteria score was not significantly correlated with quality $\left(\mathrm{r}_{\mathrm{s}}=0.02, P=.91\right)$.

\section{Discussion}

In this study, we found that the overall quality of information was incomplete, because websites had an average score of 6.47 of 20 total points. The Internet has become a part of daily life for Americans, and more patients are using it for their health information needs. ${ }^{38}$ Patients are even searching the Internet as their first source of health information, before physician consultation. ${ }^{39,40}$ However, there is concern about the quality of health information that patients encounter. Many studies ${ }^{29,34,35,41-43}$ have shown that the quality of online health information, particularly in orthopaedics, is substandard. This may negatively influence patients' expectations about their diagnosis and treatment plan and change the dynamic of the patient-physician relationship. ${ }^{16,17}$ The effect of incomplete health information on those with rotator cuff disease is problematic because it is the most common disability of the shoulder. ${ }^{44}$ Despite this fact, the information that was provided by the assessed websites, although incomplete, was indeed helpful and valuable to patients seeking to learn about rotator cuff repair.

This study has shown that many websites failed to explain salient postoperative topics that could affect one's expectations of the requirements for a successful recovery. Only $13 \%$ offered advice for when to consult their surgeon after surgery, and $12 \%$ explained the effect of a patient's general health conditions (i.e., smoking, diabetes, etc) on recovery. In contrast, $60 \%$ of websites mentioned the signs and symptoms of a rotator cuff tear, and more than $40 \%$ of websites explained the surgical options for treatment. The lack of discussion on the breadth of information pertinent to a successful rotator cuff repair could cause patients to form unrealistic expectations for their recovery.

The analysis of reading level showed that only 1 article met a sixth-grade reading level $(2.1 \%)$, which is similar to results published by other authors. ${ }^{23,24,28,45}$ Zero websites met the recommended fifth-grade reading level for healthcare information recently proposed by the Joint Commission. ${ }^{36}$ These findings are especially concerning, given that Medicare insures the largest population of patients at risk for rotator cuff tears in the United States, ${ }^{46}$ and the average reading level for a Medicare beneficiary is at a fifth-grade level. ${ }^{47}$ Despite the failure of websites to meet the reading level requirement, we did not find reading level to be significantly correlated with quality. This is in contrast to prior studies ${ }^{23,24,27}$ and could mean that information that is more difficult to read does not simply equate to a better quality source of information.

The average JAMA score in this study was 2.34, which is relatively higher than scores from previous studies $(1.43-2.1)$ in the orthopaedic literature. ${ }^{2,30,32,45}$ However, a significant relationship between JAMA score and quality was not found, and thus website transparency and disclosure of sources does not necessarily enhance the quality of information.

The percentage of HONcode-certified websites was evaluated to assess the reliability and credibility of online information on rotator cuff tears and determine its relationship to quality. It was found that $29.7 \%$ of websites were HONcode certified, which is higher than investigations on Tommy John injuries $(3.5 \%),{ }^{23}$ femoroacetabular impingement $(8 \%),{ }^{48}$ total ankle replacement $(8 \%),{ }^{33}$ and anterior cruciate ligament reconstruction $(17 \%){ }^{32}$ The higher number could be attributed to our publication being more recent and increasing awareness of the importance of certification. Interestingly, HONcode-certified websites had lower quality, although this statistic was not statistically 
Table 3. Summary of Quality of Results

\begin{tabular}{lc}
\hline \multicolumn{1}{c}{ Indicator } & Mean Quality (Maximum, 20) \\
\hline All websites & $6.47 \pm 5.21$ \\
Top 5 websites & 16.30 \\
$\quad$ http://www.orthop.washington.edu/?q=patient-care/articles/shoulder/repair-of- \\
$\quad$ rotator-cuff-tears.html & $<.001$ \\
http://www.orthop.washington.edu/?q=patient-care/articles/sports/arthroscopic- & \\
$\quad$ shoulder-surgery-for-the-treatment-of-rotator-cuff-tears & 5.51 \\
https://www.healthgrades.com/procedures/rotator-cuff-surgery & $9.03 \pm 5.59$ \\
https://drmillett.com/double-row-arthroscopic-rotator-cuff-repair-for-rotator-cuff- & $6.65 \pm 3.90$ \\
$\quad$ tears/ & Not significantly correlated with quality \\
https://orthoinfo.aaos.org/en/treatment/rotator-cuff-tears-surgical-treatment-options/ & Not significantly correlated with quality \\
All remaining websites & $8.33 \pm 4.80$ \\
Search term: rotator cuff repair & .15 \\
Search term: rotator cuff surgery & $6.18 \pm 4.66$ \\
FK grade level & .85 \\
JAMA benchmark criteria &
\end{tabular}

FK, Flesch-Kincaid; JAMA, Journal of the American Medical Association.

significant. Furthermore, 5 of the bottom 6 websites were HONcode certified. These articles came from health information services such as "WebMD, Mayo Clinic, Healthline, and MedlinePlus," all of which likely possess greater capabilities for search engine optimization and can generate additional "off-topic" articles for a given search. ${ }^{49}$ Although HONcode certification is an indicator of credibility, future authors researching the quality of online information should continue to study it to better define its relationship to quality.

Dalton et al ${ }^{45}$ performed an evaluation of websites on rotator cuff tears and evaluated quality of treatment with the DISCERN instrument. ${ }^{50}$ They found that the quality of available information is poor and the readability is inappropriately high. This study has similar findings using a novel scoring system to specifically query topics related to rotator cuff repair, which provides further confirmatory findings that online resources for patient education continue to be lacking.

\section{Limitations}

There are several limitations that must be mentioned in the context of the presented results. First, the scoring system used covers the breadth of information on rotator cuff repair, but it is not validated and standardized. Moreover, the study results are only applicable insofar as the search terms used, "rotator cuff repair" and "rotator cuff surgery," and the date in which they were entered. The Internet is constantly changing, and it is possible new search results and ranks could be generated on another search date. Although this could be true, similar results published by Dalton et al. ${ }^{45}$ a few years before this publication makes this unlikely in the near future. Also, it is possible that websites outside the top 25 could have contained high-quality information. However, it has been shown that Internet consumers only use the first 10 search results, ${ }^{51}$ and therefore, the search was restricted to be consistent with other investigations of Internet information. . $3,30,31,52,53$

\section{Conclusion}

The quality of patient-level information on rotator cuff repair on the Internet is both incomplete and written at a reading level higher than current recommendations. Information quality is not significantly correlated with reading level or JAMA criteria and does not depend on the search term used or HONcode certification.

\section{References}

1. Yamamoto A, Takagishi K, Osawa T, et al. Prevalence and risk factors of a rotator cuff tear in the general population. J Shoulder Elbow Surg 2010;19:116-120.

2. Colvin AC, Egorova N, Harrison AK, Moskowitz A, Flatow EL. National trends in rotator cuff repair. J Bone Joint Surg Am 2012;94:227-233.

3. Katthagen JC, Bucci G, Moatshe G, Tahal DS, Millett PJ. Improved outcomes with arthroscopic repair of partialthickness rotator cuff tears: A systematic review. Knee Surg Sports Traumatol Arthrosc 2018;26:113-124.

4. Millett PJ, Horan MP, Maland KE, Hawkins RJ. Long-term survivorship and outcomes after surgical repair of fullthickness rotator cuff tears. J Shoulder Elbow Surg 2011;20:591-597.

5. Millett PJ, Warth RJ, Dornan GJ, Lee JT, Spiegl UJ. Clinical and structural outcomes after arthroscopic singlerow versus double-row rotator cuff repair: A systematic review and meta-analysis of level I randomized clinical trials. J Shoulder Elbow Surg 2014;23:586-597.

6. Warth RJ, Dornan GJ, James EW, Horan MP, Millett PJ. Clinical and structural outcomes after arthroscopic repair of full-thickness rotator cuff tears with and without 
platelet-rich product supplementation: A meta-analysis and meta-regression. Arthroscopy 2015;31:306-320.

7. Watson ST, Robbins CB, Bedi A, Carpenter JE, Gagnier JJ, Miller BS. Comparison of outcomes 1 year after rotator cuff repair with and without concomitant biceps surgery. Arthroscopy 2017;33:1928-1936.

8. Noyes MP, Ladermann A, Denard PJ. Functional outcome and healing of large and massive rotator cuff tears repaired with a load-sharing rip-stop construct. Arthroscopy 2017;33:1654-1658.

9. Liu XN, Yang CJ, Lee GW, Kim SH, Yoon YH, Noh KC. Functional and radiographic outcomes after arthroscopic transosseous suture repair of medium sized rotator cuff tears. Arthroscopy 2018;34:50-57.

10. Bhatia S, Greenspoon JA, Horan MP, Warth RJ, Millett PJ. Two-year outcomes after arthroscopic rotator cuff repair in recreational athletes older than 70 years. Arthroscopy 2015;43:1737-1742.

11. Rossi LA, Atala NA, Bertona A, et al. Long-term outcomes after in situ arthroscopic repair of partial rotator cuff tears. Arthroscopy 2019;35:698-702.

12. Anderson M, Perrin A, Jiang J, Kumar M. 10\% of Americans don't use the internet. Who are they? Pew Research Center. Available at: https://www.pewresearch. org/fact-tank/2019/04/22/some-americans-dont-use-theinternet-who-are-they/. Accessed April 25, 2019.

13. Lenart BA, Martens KA, Kearns KA, Gillespie RJ, Zoga AC, Williams GR. Treatment of massive and recurrent rotator cuff tears augmented with a poly-l-lactide graft, a preliminary study. J Shoulder Elbow Surg 2015;24:915-921.

14. Medlock S, Eslami S, Askari M, et al. Health informationseeking behavior of seniors who use the Internet: a survey. J Med Internet Res 2015;17:e10.

15. Teunis T, Lubberts B, Reilly BT, Ring D. A systematic review and pooled analysis of the prevalence of rotator cuff disease with increasing age. J Shoulder Elbow Surg 2014;23:1913-1921.

16. Nwosu CR, Cox BM. The impact of the Internet on the doctor-patient relationship. Health Informatics J 2000;6: 156-161.

17. Gerber BS, Eiser AR. The patient physician relationship in the Internet age: future prospects and the research agenda. J Med Internet Res 2001;3:E15.

18. Mancuso CA, Altchek DW, Craig EV, et al. Patients' expectations of shoulder surgery. J Shoulder Elbow Surg 2002;11:541-549.

19. Mancuso CA, Jout J, Salvati EA, Sculco TP. Fulfillment of patients' expectations for total hip arthroplasty. J Bone Joint Surg Am 2009;91:2073-2078.

20. Mancuso CA, Salvati EA, Johanson NA, Peterson MG, Charlson ME. Patients' expectations and satisfaction with total hip arthroplasty. J Arthroplasty 1997;12: 387-396.

21. Iversen MD, Daltroy LH, Fossel AH, Katz JN. The prognostic importance of patient pre-operative expectations of surgery for lumbar spinal stenosis. Patient Educ Couns 1998;34:169-178.

22. Henn RF 3rd, Kang L, Tashjian RZ, Green A. Patients' preoperative expectations predict the outcome of rotator cuff repair. J Bone Joint Surg Am 2007;89:1913-1919.
23. Johnson CC, Garcia GH, Liu JN, Stepan JG, Patel RM, Dines JS. Internet resources for Tommy John injuries: what are patients reading? J Shoulder Elbow Surg 2016;25: e386-e393.

24. Garcia GH, Taylor SA, Dy CJ, Christ A, Patel RM, Dines JS. Online resources for shoulder instability: what are patients reading? J Bone Joint Surg Am 2014;96:e177.

25. Fabricant PD, Dy CJ, Patel RM, Blanco JS, Doyle SM. Internet search term affects the quality and accuracy of online information about developmental hip dysplasia. J Pediatr Orthop 2013;33:361-365.

26. Dy CJ, Taylor SA, Patel RM, Kitay A, Roberts TR, Daluiski A. The effect of search term on the quality and accuracy of online information regarding distal radius fractures. J Hand Surg Am 2012;37:1881-1887.

27. Dy CJ, Taylor SA, Patel RM, McCarthy MM, Roberts TR, Daluiski A. Does the quality, accuracy, and readability of information about lateral epicondylitis on the internet vary with the search term used? Hand (N Y) 2012;7: 420-425.

28. Schairer WW, Kahlenberg CA, Sculco PK, Nwachukwu BU. What is the quality of online resources about pain control after total knee arthroplasty? J Arthroplasty 2017;32:3616-3620.el.

29. Ottenhoff JSE, Kortlever JTP, Teunis T, Ring D. Factors associated with quality of online information on trapeziometacarpal arthritis. J Hand Surg Am 2018;43: 889-896.e5.

30. Nassiri M, Bruce-Brand RA, O’Neill F, Chenouri S, Curtin PT. Surfing for hip replacements: Has the "internet tidal wave" led to better quality information. J Arthroplasty 2014;29:1339-1344.el.

31. Nason GJ, Baker JF, Byrne DP, Noel J, Moore D, Kiely PJ. Scoliosis-specific information on the internet: has the "information highway" led to better information provision? Spine (Phila Pa 1976) 2012;37:E1364-E1369.

32. Bruce-Brand RA, Baker JF, Byrne DP, Hogan NA, McCarthy T. Assessment of the quality and content of information on anterior cruciate ligament reconstruction on the internet. Arthroscopy 2013;29:1095-1100.

33. Elliott AD, Bartel AF, Simonson D, Roukis TS. Is the internet a reliable source of information for patients seeking total ankle replacement? J Foot Ankle Surg 2015;54:378-381.

34. Mehta MP, Swindell HW, Westermann RW, Rosneck JT, Lynch TS. Assessing the readability of online information about hip arthroscopy. Arthroscopy 2018;34:2142-2149.

35. Ghodasra JH, Wang D, Jayakar RG, et al. The assessment of quality, accuracy, and readability of online educational resources for platelet-rich plasma. Arthroscopy 2018;34: 272-278.

36. The Joint Commission. Advancing effective communication, cultural competence, and patient- and family-centered care: A roadmap for hospitals. Oakbrook Terrace, IL: The Joint Commission, 2014.

37. Boyer C, Selby M, Appel RD. The Health On the Net Code of Conduct for medical and health web sites. Stud Health Technol Inform 1998;52:1163-1166 (Pt 2).

38. Marton C, Wei Choo C. A review of theoretical models of health information seeking on the web. J Documentation 2012;68:330-352. 
39. Stevenson FA, Kerr C, Murray E, Nazareth I. Information from the Internet and the doctor-patient relationship: The patient perspective-A qualitative study. BMC Fam Pract 2007;8:47.

40. Kivits J. Informed patients and the internet: A mediated context for consultations with health professionals. J Health Psychol 2006;1 1:269-282.

41. Butler L, Foster NE. Back pain online: a cross-sectional survey of the quality of web-based information on low back pain. Spine (Phila Pa 1976) 2003;28:395-401.

42. Li L, Irvin E, Guzman J, Bombardier C. Surfing for back pain patients: The nature and quality of back pain information on the Internet. Spine (Phila Pa 1976) 2001;26: 545-557.

43. Guo WJ, Wang WK, Xu D, Qiao Z, Shi YL, Luo P. Evaluating the quality, content and readability of online resources for failed back spinal surgery. Spine (Phila Pa 1976) 2019;44:494-502.

44. Chakravarty K, Webley M. Shoulder joint movement and its relationship to disability in the elderly. J Rheumatol 1993;20:1359-1361.

45. Dalton DM, Kelly EG, Molony DC. Availability of accessible and high-quality information on the Internet for patients regarding the diagnosis and management of rotator cuff tears. J Shoulder Elbow Surg 2015;24:e135-e140.

46. Jensen AR, Cha PS, Devana SK, et al. Evaluation of the trends, concomitant procedures, and complications with open and arthroscopic rotator cuff repairs in the medicare population. Orthop J Sports Med 2017;5: 2325967117731310.

47. United States Government Accountability Office Report to Congressional Requesters. Medicare: Communications to beneficiaries on the prescription drug benefit could be improved. http://www.gao.gov/new.items/d06654.pdf. Accessed January 11, 2019.

48. Lee S, Shin JJ, Haro MS, Song SH, Nho SJ. Evaluating the quality of Internet information for femoroacetabular impingement. Arthroscopy 2014;30:1372-1379.

49. Catley J. Hospital marketing lessons from the Mayo Clinic. MD Connect 2014.

50. Charnock D, Shepperd S, Needham G, Gann R. DISCERN: An instrument for judging the quality of written consumer health information on treatment choices. J Epidemiol Community Health 1999;53:105-111.

51. Eysenbach G, Kohler C. How do consumers search for and appraise health information on the world wide web? Qualitative study using focus groups, usability tests, and in-depth interviews. BMJ 2002;324:573-577.

52. Sullivan TB, Anderson JT, Ahn UM, Ahn NU. Can Internet information on vertebroplasty be a reliable means of patient self-education? Clin Orthop Relat Res 2014;472:1597-1604.

53. Weil AG, Bojanowski MW, Jamart J, Gustin T, Leveque M. Evaluation of the quality of information on the Internet available to patients undergoing cervical spine surgery. World Neurosurg 2014;82:e31-e39. 
Appendix 1. Website URLs With Score Breakdown Listed in Order of Highest Score to Lowest Score

URL

http://www.orthop.washington.edu/?q=patient-care/articles/sports/arthroscopic-shouldersurgery-for-the-treatment-of-rotator-cuff-tears

https://www.healthgrades.com/procedures/rotator-cuff-surgery

https://drmillett.com/double-row-arthroscopic-rotator-cuff-repair-for-rotator-cuff-tears/

https://orthoinfo.aaos.org/en/treatment/rotator-cuff-tears-surgical-treatment-options/

https://www.healthline.com/health/rotator-cuff-repair

https://www.hopkinsmedicine.org/healthlibrary/test_procedures/orthopaedic/rotator_cuff_ repair_92,P07682

https://medlineplus.gov/ency/article/007207.htm

https://www.sports-health.com/sports-injuries/shoulder-injuries/rotator-cuff-repair-surgery

http://www.orthosports.com.au/content_common/pg-open-rotator-cuff-repair.seo

https://www.webmd.com/pain-management/rotator-cuff-surgery

https://www.medigo.com/en-us/procedure-pages/orthopedics/rotator-cuff-surgery

https://newsok.com/article/3882852/whats-it-like-to-have-your-rotator-cuff-repaired

https://www.howardluksmd.com/education/common-injuries/recovery-from-rotator-cuffsurgery/

https://www.g2orthopedics.com/rotator-cuff-surgery-faqs/

http://www.kneeandshouldersurgery.com/shoulder-disorders/rotator-cuff-disorders/rotatorcuff-tears/

https://sportssurgerychicago.com/rotator-cuff-repair-protocol-treatment-westchester-

oakbrook-hinsdale-il/

https://www.shoulderdoc.co.uk/article/62

https://www.massgeneral.org/ortho/services/sports/rehab/Rotator\%20cuff\%20repair\%

20rehabilitation\%20protocol.pdf

https://www.nordorthopaedics.com/en/shoulder-surgery/rotatory-cuff-tear-repair

https://en.wikipedia.org/wiki/Rotator_cuff

https://www.rothmaninstitute.com/specialties/treatments/rotator-cuff-surgery

https://myhealth.alberta.ca/Health/aftercareinformation/pages/conditions.aspx?hwid=ug3498

https://www.verywellhealth.com/rotator-cuff-tear-surgery-2549776

https://my.clevelandclinic.org/health/diseases/8291-rotator-cuff-tears-overview

https://www.arksurgicalhospital.com/5-tips-recovering-rotator-cuff-surgery-returning-game/

https://www.mayoclinic.org/diseases-conditions/rotator-cuff-injury/diagnosis-treatment/drc20350231

https://www.webmd.com/pain-management/rotator-cuff-tear

https://www.verywellhealth.com/rehab-after-rotator-cuff-surgery-2549905

https://www.hopkinsmedicine.org/orthopaedic-surgery/specialty-areas/shoulder/treatments-

procedures/failed-rotator-cuff-repairs.html

https://www.anationinmotion.org/value/rotator-cuff/

https://www.premierortho.com/physical-therapy/long-recovery-period-shoulder-surgery/

https://healthfully.com/average-following-rotator-cuff-surgery-5418081.html

https://kneeandshoulderclinic.com.au/shoulders/surgical-conditions/rotator-cuff-repair/

https://www.medstargeorgetown.org/our-services/orthopaedics/conditions/shoulder-

conditions/rotator-cuff-surgery/

https://truesportsphysicaltherapy.com/what-can-i-expect-after-rotator-cuff-surgery/

http://www.stoneclinic.com/rotator-cuff-repair-rehab-protocol/

https://www.regenexx.com/rotator-cuff-tear-healing-without-surgery/

https://orthoinfo.aaos.org/en/diseases-conditions/rotator-cuff-tears/

https://www.howardluksmd.com/orthopedic-social-media/do-i-need-rotator-cuff-tear-surgery/

https://www.sports-health.com/treatment/shoulder-injury-treatment/different-types-rotator-

cuff-surgery

https://www.mayoclinic.org/diseases-conditions/rotator-cuff-injury/symptoms-causes/syc-

20350225

https://www.healthline.com/health/rotator-cuff-injury-stretches

https://www.webmd.com/pain-management/what-is-my-rotator-cuff

https://medlineplus.gov/ency/patientinstructions/000357.htm

https://www.mocnyc.com/arthroscopic-rotator-cuff-repair/

https://medlineplus.gov/ency/presentations/100229_1.htm
Pre-Score Sx-Score Post-Score Total score

$\begin{array}{llll}4 & 7 & 6.25 & 17.25\end{array}$

$\begin{array}{llll}2.75 & 6 & 7 & 15.75\end{array}$

$\begin{array}{llll}3.75 & 5 & 7 & 15.75\end{array}$

